Synthesis of Natural

Products and

Potential Drugs

\section{Synthesis of (-)-Oseltamivir}<smiles>CCC(CC)OCC=O</smiles>

A $(17.3 \mathrm{mmol})$<smiles>CC(=O)N/C=C\[N+](=O)[O-]</smiles>
(11.5 mmol)

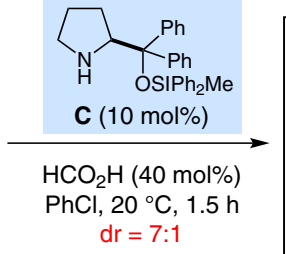

$\mathrm{dr}=7: 1$

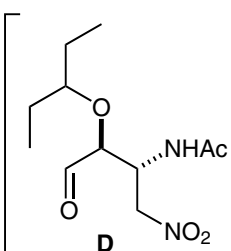

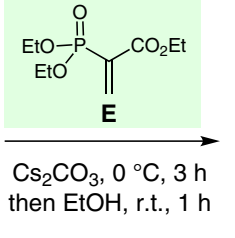

then $\mathrm{EtOH}$, r.t., $1 \mathrm{~h}$<smiles>CCOC(=O)C1=CC(OC(CC)CC)[C@H](NC)[C@H]([N+](=O)[O-])C1</smiles>

\section{Key words}

oseltamivir

neuraminidase inhibitors

asymmetric Michael addition

organocatalysis

SYNFACTH<smiles>CCOC(=O)C1=CC(OC(CC)CC)[C@H](NC(C)=O)C(N)C1</smiles>

(-)-Oseltamivir $28 \%$ overall from $B$
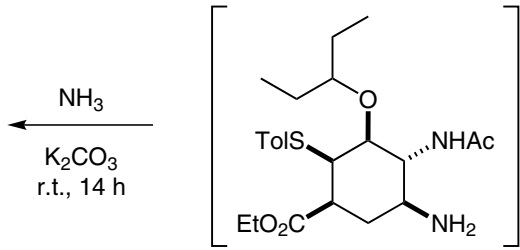

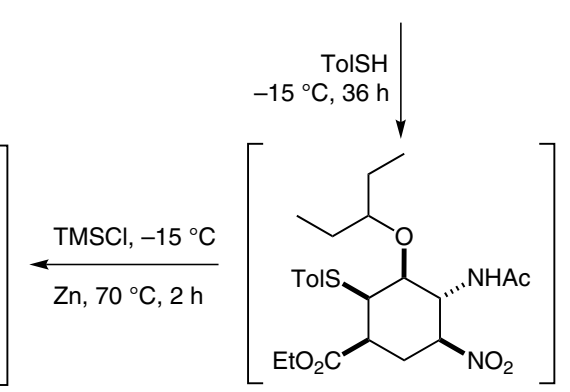

Significance: A remarkably short and efficient gram-scale synthesis of the neuraminidase inhibitor (-)-oseltamivir is reported featuring an organocatalytic Michael addition as the first step. The sequence requires only one pot and was achieved without evaporation of solvent or solvent exchange. The overall yield for the gram-scale synthesis was $28 \%$ from the (Z)-nitroalkene $\mathbf{B}$.
Comment: A thorough investigation of the mechanism of the initial Michael addition established optimum conditions which include (1) the use of a bulky $O$-silyl-substituted diphenylprolinol catalyst (C), (2) chlorobenzene as the solvent, and (3) the addition of formic acid to accelerate the reaction and to increase diastereo- and enantioselectivity. This represents a substantial improvement on an earlier synthesis $(\mathrm{H}$. Ishikawa et al. Chem. Eur. J. 2010, 16, 12616). 